\title{
Bruguierivorax albus gen. nov. sp. nov. Isolated from Mangrove Sediment and Proposal of Bruguierivoracaceae fam. nov
}

\author{
Mi Li ${ }^{1} \cdot$ Kai Liu' ${ }^{1}$ Yonghong Liu ${ }^{1}$ Chenghai Gao ${ }^{1} \cdot$ Xiangxi Yi $^{1}$
}

Received: 25 August 2020 / Accepted: 27 November 2020 / Published online: 19 January 2021

(c) The Author(s) 2021

\begin{abstract}
A novel Gram-negative, motile, aerobic rod-shaped bacterium designated BGMRC $2031^{\mathrm{T}}$ was isolated from mangrove sediment collected from Guangxi Province, China. Optimal growth occurred at $28^{\circ} \mathrm{C}$ and pH 7.0-8.0 in the presence of $1 \%(\mathrm{w} / \mathrm{v}$ ) $\mathrm{NaCl}$. Alignment based on $16 \mathrm{~S}$ rRNA gene sequences indicated that strain BGMRC $2031^{\mathrm{T}}$ is most closely related to Sodalis praecaptivus $\mathrm{HS1}^{\mathrm{T}}$ (95.6\%, sequence similarity), followed by Biostraticola tofi DSM $19580^{\mathrm{T}}(95.5 \%)$, Sodalis glossinidius DSM $16929^{\mathrm{T}}(95.4 \%)$, and Brenneria goodwinii FRB $141^{\mathrm{T}}(94.9 \%)$ sequence similarity. Phylogenetic analysis based on 16S rRNA gene sequences showed that strain BGMRC $2031^{\mathrm{T}}$ formed a distinct branch in a robust cluster and revealed that strain BGMRC $2031^{\mathrm{T}}$, genera Biostraticola and Sodalis, formed a novel family-level clade in the order Enterobacterales. The novel strain showed an average nucleotide similarity of $74.7 \%, 74.2 \%$, and $73.1 \%$ for $S$. praecaptivus $\mathrm{HS}^{\mathrm{T}}{ }^{\mathrm{T}}$, S. glossinidius DSM $16929^{\mathrm{T}}$, and $B$. tofi DSM $19580^{\mathrm{T}}$, respectively. The genomes of the BGMRC $2031^{\mathrm{T}}$ shared the presence of a riboflavin synthesis gene cluster. The menaquinones of strain BGMRC $2031^{\mathrm{T}}$ were MK-8 and Q-8, which were similar to those of genus Biostraticola. The major fatty acids ( $>10 \%$ ) were $\mathrm{C}_{16: 0}\left(19.9 \%\right.$ ), summed feature 2 (iso- $\mathrm{C}_{16: 1}$ and/or $\mathrm{C}_{14: 0} 3-\mathrm{OH}, 18.10 \%$ ), summed feature $3\left(\mathrm{C}_{16: 1} \omega 7 c\right.$ and/or $\left.\mathrm{C}_{16: 1} \omega 6 c, 15.3 \%\right), \mathrm{C}_{12: 0}(13.9 \%), \mathrm{C}_{17: 0}$ cyclo (11.4\%), and $\mathrm{C}_{14: 0}(10.4 \%)$. The main polar lipids were phosphatidyl methylethanolamine, phosphatidyl glycerol, diphosphatidyl glycerol, phosphatidyl inositol, one unidentified phospholipid, and one unknown polar lipid. The G+C content of strain BGMRC $2031^{\mathrm{T}}$ was $55.4 \%$. Strain BGMRC $2031^{\mathrm{T}}$ could extend the mean lifespan and maximum lifespan of Caenorhabditis elegans by $4.5 \%$ and $12.5 \%$, respectively. Overall, the results of this study indicate that BGMRC $2031^{\mathrm{T}}$ is a novel species in a new genus, for which the name Bruguierivorax albus gen. nov. sp. nov. is proposed, and the type of strain is designated as BGMRC $2031^{\mathrm{T}}(=\mathrm{NBRC}$ $111907^{\mathrm{T}}=$ KCTC $52119^{\mathrm{T}}$ ). In addition, a novel family, Bruguierivoracaceae fam. nov., is proposed to accommodate the genera Bruguierivorax, Biostraticola, and Sodalis.
\end{abstract}

The GenBank accession numbers for the 16S rRNA gene sequence and draft genome sequence of Bruguierivorax albus BGMRC $2031^{\mathrm{T}}$ are MN059649 and SZPQ00000000, respectively. Transmission electron micrographs of cells of strain BGMRC $2031^{\mathrm{T}}$, polar lipids of strain BGMRC $2031^{\mathrm{T}}$ and Biostraticola tofi DSM $19580^{\mathrm{T}}$, Maximum-Likelihood tree, and Minimum Evolution tree are available as supplementary figures in Current microbiology Online.

Supplementary information The online version of this article (https://doi.org/10.1007/s00284-020-02311-w) contains supplementary material, which is available to authorized users.

Chenghai Gao

gaoch@gxtcmu.edu.cn

Xiangxi Yi

yixiangxi2017@163.com

1 Institute of Marine Drugs, School of Pharmaceutical Sciences, Guangxi University of Chinese Medicine, NO. 13 Wuhe Rood, Nanning 530200, People's Republic of China

\section{Introduction}

The order Enterobacterales is a large group within the class Gammaproteobacteria which was revised in 2016 by Adeolu et al. [1]. This order is characterized by its non-sporeforming, rod-shaped bacteria, as well as its Gram-negative and facultatively anaerobic characteristics [1]. At the time of its revision, the Enterobacterales comprised seven families according to the EzTaxon database, Enterobacteriaceae, Erwiniaceae, Pectobacteriaceae, Yersiniaceae, Hafniaceae, Morganellaceae, and Budviciaceae [1].

The genera Biostraticola and Sodalis were first proposed by Verbarg et al. [2] and Dale et al. [3], respectively. In 2016, Biostraticola and Sodalis were affiliated to two families, Enterobacteriaceae and Pectobacteriaceae, respectively, based on their genome phylogeny and taxonomy [1]. At the time of writing, the genus Biostraticola 
contained a single species, B. tofi, while Sodalis contained two validly named species (S. praecaptivus [4] and $S$. glossinidius [3]) and two candidatus species (Candidatus S. melophagi [5] and Candidatus S. baculum [6]). Two Candidatus strains were live in symbiosis with various groups of insects and, respectively, symbiose relationships with Melophagus ovinus and Hemipteran insects. To date, the majority of Sodalis members have been found in several insect groups, and $S$. praecaptivus has been found in human hand wounds [4, 6]. The strain S. lignotolerans $159 \mathrm{R}$ was isolated from an anaerobic lignin degrading consortium.

In our study of microbial biodiversity in medicinal mangrove plants, strain BGMRC $2031^{\mathrm{T}}$ was isolated from a Bruguiera gymnorrhiza rhizosphere soil sample. Comparative 16S rRNA gene sequence analysis showed that strain BGMRC $2031^{\mathrm{T}}$ was closely related to species in the genera Biostraticola (95.5\%) and Sodalis (95.4-95.6\%). However, strain BGMRC $2031^{\mathrm{T}}$ could not be assigned to any species of the genera Biostraticola or Sodalis because of its low sequence similarity with the two type strains $(\leq 95.6 \%)$. Therefore, the present study is conducted to report the taxonomic characterization of the new isolate, BGMRC $2031^{\mathrm{T}}$.

\section{Materials and Methods}

\section{Bacterial Strain and Culture Conditions}

Strain BGMRC $2031^{\mathrm{T}}$ was isolated from sediment of Bruguiera gymnorrhiza roots collected from Guangxi Province, China ( $\left.21^{\circ} 55^{\prime} \mathrm{N}, 108^{\circ} 50^{\prime} \mathrm{E}\right)$. Samples were immediately stored in sterile plastic bags at $4{ }^{\circ} \mathrm{C}$, then transported to the laboratory within $12 \mathrm{~h}$. Soil $(2 \mathrm{~g})$ was added to $20 \mathrm{~mL}$ of sterilized seawater, then shaken at $37^{\circ} \mathrm{C}$ for $1 \mathrm{~h}$. Next, $1 \mathrm{~mL}$ of the suspension was transferred to $9 \mathrm{~mL}$ sterilized sea water and serially diluted to $10^{-2}, 10^{-3}, 10^{-4}$, and $10^{-5}$. The serial dilutions of the samples $(200 \mu \mathrm{L})$ were subsequently plated onto R2A medium ( $0.5 \mathrm{~g}$ yeast extract powder, $0.5 \mathrm{~g}$ peptone, $0.5 \mathrm{~g}$ casein hydrolysate, $0.5 \mathrm{~g}$ glucose, $0.5 \mathrm{~g}$ starch, $0.3 \mathrm{~g} \mathrm{~K}_{2} \mathrm{HPO}_{4}, 0.024 \mathrm{~g} \mathrm{MgSO}_{4}, 0.3 \mathrm{~g}$ sodium pyruvate, $15.0 \mathrm{~g}$ agar, $1 \mathrm{~L}$ seawater, $\mathrm{pH} 7.2$ ), then incubated at $28{ }^{\circ} \mathrm{C}$ for 1 week. Single colony was selected and purified on modified Yeast Malt Extract (ISP2) (2.0 g yeast extract, $2.0 \mathrm{~g}$ malt extract, $2.0 \mathrm{~g} \mathrm{D}-(+)$-glucose anhydrous, $15.0 \mathrm{~g}$ agar powder and $1 \mathrm{~L}$ seawater) at $28{ }^{\circ} \mathrm{C}$. Strain BGMRC $2031^{\mathrm{T}}$ was isolated using the preceding method, then preserved in $20 \%$ (v/v) glycerol suspensions at $-80^{\circ} \mathrm{C}$. The reference strain, B. tof DSM $19580^{\mathrm{T}}$, was obtained from the Leibniz Institut DSMZ-German Collection of Microorganisms and Cell Cultures GmbH.

\section{Morphological and Physiological Characteristics}

Morphological and physiological characteristics were observed on modified ISP2 medium unless stated. Growth and colony morphology were observed after 2 days incubation at $28^{\circ} \mathrm{C}$. Cell morphology was observed using a scanning electron microscope (FEI Quanta 250 Environmental Scanning Electron Microscope), and the flagellum of the strain was observed via transmission electron microscopy (Hitachi Transmission Electron Microscope HT7700) after growth on ISP 2 at $28{ }^{\circ} \mathrm{C}$ for 2 days. Cell motility determination was conducted by observing the development of turbidity in a tube using ISP2 semisolid medium containing $0.4 \%$ agar [7]. Gram staining was determined on ISP2 plates following the protocols described by Gerhardt et al. [8]. Oxidase activity was examined using $1 \%(\mathrm{w} / \mathrm{v}) \mathrm{N}, N$, $N$ ', $N$ '-tetramethyl-p-phenylenediamine reagent. Catalase activity was assessed using $3 \%(\mathrm{w} / \mathrm{v}) \mathrm{H}_{2} \mathrm{O}_{2}$ solution [9]. Growth at various concentrations of $\mathrm{NaCl}(0 \%-15 \%$, w/v, with an interval of $1.0 \%$ ), was tested on ISP2 agar (Difco) at $28{ }^{\circ} \mathrm{C}$. The temperature range was determined by incubating cells in ISP2 medium broth at $4{ }^{\circ} \mathrm{C}, 10{ }^{\circ} \mathrm{C}$, $15{ }^{\circ} \mathrm{C}, 20^{\circ} \mathrm{C}, 25{ }^{\circ} \mathrm{C}, 28{ }^{\circ} \mathrm{C}, 37{ }^{\circ} \mathrm{C}, 40{ }^{\circ} \mathrm{C}$, and $45{ }^{\circ} \mathrm{C}$ for 2 weeks. The $\mathrm{pH}$ range for growth ( $\mathrm{pH} 4.0-12.0$ at intervals of $1 \mathrm{pH}$ unit) was tested in ISP2 broth at $28^{\circ} \mathrm{C}$ using the buffer system developed by $\mathrm{Xu}$ et al. [10]. Cultural characteristics were determined by observing growth of the strain at $28^{\circ} \mathrm{C}$ for 2 weeks on ISP2, ISP3, ISP4, ISP5, and ISP7 agar plates, lysogeny broth (LB agar), R2A agar, and tryptic soy agar. ISCC-NBS color charts [11] were used to assess colony colors. Biochemical tests, including $\mathrm{H}_{2} \mathrm{~S}$ production, hydrolysis of cellulose, gelatin, starch, Tweens 20,40, and 80, were performed using the methods described by Tindall [12]. Coagulation and peptonisation of milk were evaluated as described by Gonzalez [13]. Carbohydrate metabolism was determined using API ZYM and API 20E strips (BioMérieux, Marcyl'Etoile, France) according to the manufacturer's instructions. Anaerobic fermentation was evaluated using the API 50CH system (BioMérieux). The incubation temperature for all API kits was $28{ }^{\circ} \mathrm{C}$, and results were observed after $48 \mathrm{~h}$.

\section{Chemotaxonomic Characterization}

Cell biomass for the chemotaxonomic characterization was obtained from ISP2 medium after incubation at $28{ }^{\circ} \mathrm{C}$ for 3 days. Polar lipids were extracted as described by Kamekura [14] and identified by two-dimensional thinlayer chromatography (TLC) on silica gel $60 \mathrm{GF}_{254}$ plates (Merck KGaA, Darmstadt Germany) that had been sprayed with ethanolic molybdophosphoric acid, molybdenum 
blue, and ninhydrin after two-dimensional TLC [15]. Respiratory quinones were extracted and analyzed using reverse-phase HPLC $[16,17]$. Cellular fatty acid composition was analyzed by gas chromatography (G6890N; Agilent Technologies, Savage, MD, USA) and identified using the Sherlock Microbial Identification System (version 6.0) according to the manufacturer's instructions and as previously described [18].

\section{Phylogenetic Analyses}

PCR amplification of strain BGMRC $2031^{\mathrm{T}}$ with the universal primers $27 \mathrm{~F}$ and $1492 \mathrm{R}$ and subsequent $16 \mathrm{~S}$ rRNA gene sequencing [19] were conducted as described by $\mathrm{Li}$ et al.[20]. The purified DNA product was cloned into the pEASY-T1 vector and transformed into Escherichia coli DH5 $\alpha$ using the pEASY-T1 cloning kit. The 16S rRNA gene sequence was compared with that of recognized species using EzBioCloud (http://www.ezbiocloud.net) [21]. Multiple alignments of the sequence data were conducted using CLUSTAL X 1.83 [22]. Phylogenetic analyses were conducted based on the neighbor-joining [23], maximumlikelihood [24], and maximum-parsimony [25] algorithms using the MEGA software (version 7.0) [26]. Kimura's twoparameter model was used to calculate evolutionary distance matrices of the neighbor-joining method [27]. The topology of the phylogenetic tree was evaluated by bootstrap analysis with 1000 replicates [28].

\section{Genomic Characterization}

To further distinguish strain BGMRC $2031^{\mathrm{T}}$ from its closely related species, whole-genome sequencing was conducted by BGI (Wuhan, China) using the Illumina Hiseq 4000 system (Illumina, San Diego, CA, USA) according to the manufacturer's suggested protocols. The draft genome was assembled using SOAP de novo version 2.04, and the short oligonucleotides of the obtained results were further optimized using SOAP aligner 2.21 [29, 30]. The obtained genome sequences were annotated by using the NCBI Prokaryotic Genome Annotation Pipeline and deposited at DDBJ/ENA/ GenBank. Genomes were annotated using the Rapid Annotation Subsystems Technology (RAST) servers [31]. Genomic information of B. tofi DSM $19580^{\mathrm{T}}$ (SMCR00000000), S. praecaptivus $\mathrm{HS}^{\mathrm{T}}(\mathrm{CP} 006569.1)$, S. glossinidius DSM $16929^{\mathrm{T}}$ (GCA_000010085.1), and Candidatus S. baculum HBA(LT897836) was downloaded from GenBank and was used to evaluate genomic relatedness with strain BGMRC $2031^{\mathrm{T}}$. The average nucleotide identity (ANI) was calculated using the ANI calculator tool from EzBioCloud [32]. The estimated genome sequence-based digital DNA-DNA hybridization values were calculated using formula 2 from the online Genome-to-Genome Calculator (http://ggdc. dsmz.de/ggdc.php) as described by Meier-Kolthoff et al. [33].

\section{Effects on Lifespan of Caenorhabditis elegans}

The antiaging activities of crude extract of strain BGMRC $2031^{\mathrm{T}}$ were investigated as previously described [34]. Briefly, the strain was fermented in ISP2 liquid medium at $28^{\circ} \mathrm{C}$ and $180 \mathrm{rpm}$ for 7 days. The fermentation liquor was then extracted with ethyl acetate, after which it was concentrated and desiccated to yield crude extract [35]. Wild-type C. elegans strains (N2) were purchased from the Caenorhabditis Genetic Center (CGC) at the University of Minnesota (Minneapolis, MN, USA). Synchronized worms can eliminate variation in results due to age differences [34]; therefore, adult worms were seeded with E. coli OP50 on nematode growth medium (NGM) plates and incubated for about 2 days at $20{ }^{\circ} \mathrm{C}$. Next, $\mathrm{M} 9$ buffer $\left(0.3 \% \mathrm{KH}_{2} \mathrm{PO}_{4}, 0.6 \%\right.$ $\mathrm{Na}_{2} \mathrm{HPO}_{4}, 0.5 \% \mathrm{NaCl}, 1 \mathrm{mM} \mathrm{MgSO}{ }_{4}$ ) was poured onto the plate and gently swirled it to dislodge the worms. Alkaline hypochlorite (20\%) was subsequently used to completely lyse the adult worms, after which synchronized eggs were collected. The synchronized eggs were grown in M9 buffer overnight at $20^{\circ} \mathrm{C}$, then put on NGM plates at the L4 stage. Synchronized L4 larvae were subsequently used to analyze the life span of worms at $20^{\circ} \mathrm{C}$. Forty L4 stage larvae were randomly transferred onto fresh NGM plates seeded with dead E. coli OP50 (day 0 of lifespan), then treated with $100 \mu \mathrm{L}, 0.1 \%$ (v/v) DMSO (blank control) or $500 \mu \mathrm{g} \cdot \mathrm{mL}^{-1}$ BGMRC $2031^{\mathrm{T}}$ crude extract. The BGMRC $2031^{\mathrm{T}}$ crude extracts were dissolved in dimethyl sulfoxide, and the final concentration of DMSO was less than $0.1 \%$. During the lifespan experiments, media were exchanged every 2 days, and survival of the animals was measured daily based on touch-provoked movement. All lifespan experiments were repeated at least two independent times.

\section{Results and Discussion}

\section{Morphological and Physiological Characteristics}

Colonies of strain BGMRC $2031^{\mathrm{T}}$ were round, flat, and white with diameters of $0.5-1.0 \mathrm{~mm}$ after cultivation for 2 days on ISP 2 at $28{ }^{\circ} \mathrm{C}$. Cells of BGMRC $2031^{\mathrm{T}}$ were Gram-negative and motile. Scanning electron microscopy showed that the cells were short rods of about $0.4-0.6 \times 1.0-1.6 \mu \mathrm{m}$ (Fig. S3). No growth was observed under anaerobic conditions. Strain BGMRC $2031^{\mathrm{T}}$ growth occurred at $15{ }^{\circ} \mathrm{C}-37{ }^{\circ} \mathrm{C}$ (optimum, $28^{\circ} \mathrm{C}$ ) and pH 5.0-9.0 (optimum, $\mathrm{pH} 7.0-8.0$ ) in the presence of $0 \%-6 \%(\mathrm{w} / \mathrm{v})$ 
Table 1 Differential phenotypic characteristics of BGMRC $2031^{\mathrm{T}}$ and closely related strain Biostraticola tofi DSM $19580^{\mathrm{T}}$

\begin{tabular}{|c|c|c|}
\hline Characteristic & BGMRC $2031^{\mathrm{T}}$ & Biostraticola tofi DSM $19580^{\mathrm{T}}$ \\
\hline Colony pigmentation & White & Creamy white \\
\hline Catalase/Oxidase & \pm & \pm \\
\hline Temperature range for growth $\left({ }^{\circ} \mathrm{C}\right)$ & $15-37(28)$ & $5-30(28)$ \\
\hline $\mathrm{pH}$ range for growth & $5.0-9.0(7.0-8.0)$ & $5.0-9.0(8.0-9.0)$ \\
\hline $\mathrm{NaCl}$ range for growth $(\%, w / v)$ & $0-6(0-1)$ & $0-6(0-1)$ \\
\hline Milk coagulation and gelation & + & - \\
\hline VP test & + & - \\
\hline Sorbitol fermentation & + & - \\
\hline Rhamnose & + & + \\
\hline Melibiose & - & - \\
\hline Esterase (C4) & - & + \\
\hline Esterase lipase (C8) & - & + \\
\hline Valine arylamidase & + & - \\
\hline Cystine arylamidase & + & - \\
\hline Trypsin & + & - \\
\hline$\alpha$-Galactosidase & - & - \\
\hline$\beta$-Galactosidase & + & + \\
\hline$N$-Acetyl- $\beta$-glucosaminidase & - & - \\
\hline Polar lipids $\dagger$ & PME, PG, DPG, PI, PL, L & PME, PG, DPG, PI, PL \\
\hline Respiratory quinone & MK-8 \& Q-8 & MK-8 \& Q-8 \\
\hline
\end{tabular}

+ , positive; - , negative, nd, not determined

†PME, phosphatidylmethylethanolamine; PG, phosphatidyl glycerol; DPG, diphosphatidyl glycerol; PI, phosphatidyl inositol; PL, unidentified phospholipid; L, unidentified lipid(s)
$\mathrm{NaCl}$ (optimum, 0-1\%) (Table 1). Growth occurred on ISP2, LB, and R2A agar plates, but not ISP3, ISP4, ISP5, ISP7, or trypticase soy yeast agar plates. The strain was positive for catalase activities and negative for oxidase. Milk coagulation and peptonisation were positive, and hydrolysis of gelatin, nitrate reduction, cellulose, starch, and Tween 20,40, and 80 were negative. The differences in the physiological and biochemical characteristics of strain BGMRC $2031^{\mathrm{T}}$ and its closest related type strains are listed in Table 1 and Tables S1 and S2. Strain BGMRC $2031^{\mathrm{T}}$ and the other related species were motile and catalase positive; however, strain S. glossinidius DSM $16929^{\mathrm{T}}$ was non-motile and catalase negative. Strain BGMRC $2031^{\mathrm{T}}$ was VP, valine arylamidase, cystine arylamidase, trypsin, 2-ketogluconate, and 5-ketogluconate positive, as well as positive for milk coagulation, peptonisation and fermentation of D-mannose, D-adonitol, D-glucose, dulcitol, D-sorbitol, L-fucose, D-arabinitol, and L-arabinitol. However, the strain was negative for esterase (C4) and esterase lipase (C8), as well as fermentation of D-cellobiose. These characteristics enable strain BGMRC $2031^{\mathrm{T}}$ to be clearly distinguished from its closest phylogenetic relatives.

\section{Chemotaxonomic Characterization}

The major cellular fatty acids of strain BGMRC $2031^{\mathrm{T}}$ (>10\%) were $\mathrm{C}_{16: 0}\left(19.9 \%\right.$ ), summed feature 2 (iso- $\mathrm{C}_{16: 1}$ and/or $\left.\mathrm{C}_{14: 0} 3-\mathrm{OH}(18.1 \%)\right)$, summed feature $3\left(\mathrm{C}_{16: 1} \omega 7 c\right.$ and/or $\left.\mathrm{C}_{16: 1} \omega 6 c(15.3 \%)\right), \mathrm{C}_{12: 0}(13.9 \%), \mathrm{C}_{17: 0}$ cyclo (11.4\%), and $\mathrm{C}_{14: 0}(10.4 \%)$, whereas $\mathrm{C}_{17: 0}$ cyclo $(21.0 \%)$ and $\mathrm{C}_{16: 0}$ (20.6\%) were the predominant fatty acids of strain $B$. tofi DSM $19580^{\mathrm{T}}$ (Table S3). S. glossinidius DSM $16929^{\mathrm{T}}$ was different from BGMRC $2031^{\mathrm{T}}$ and $B$. tofi DSM $19580^{\mathrm{T}}$ in the absence of $\mathrm{C}_{19: 0}$ cyclo $\omega 8 \mathrm{c}$. BGMRC $2031^{\mathrm{T}}$ was different from B. tofi DSM $19580^{\mathrm{T}}$ based on the percentage of $\mathrm{C}_{17: 0}$ cyclo and summed feature 2 (iso- $\mathrm{C}_{16: 1}$ and/or $\mathrm{C}_{14: 0} 3-\mathrm{OH}$ ). The $\mathrm{C}_{16: 0}$ was main cellular fatty acid of BGMRC $2031^{\mathrm{T}}$ and other neighboring families (Table 2). The major polar lipids consisted of phosphatidyl methylethanolamine, phosphatidyl glycerol, diphosphatidyl glycerol, phosphatidyl inositol, one unidentified phospholipid and one unknown polar lipid (Fig. S4). The polar lipid profile of BGMRC $2031^{\mathrm{T}}$ was similar to that of B. tofi DSM $19580^{\mathrm{T}}$, while one unknown polar lipid was detected in BGMRC $2031^{\mathrm{T}}$. The menaquinones were MK-8 (60.7\%) and Q-8 (39.3\%), which were similar to those of B. tofi DSM $19580^{\mathrm{T}}$ and neighboring families (Table 2). 
Table 2 Chemotaxonomy properties of BGMRC $2031^{\mathrm{T}}$ and neighboring families

\begin{tabular}{|c|c|c|c|c|}
\hline $\begin{array}{l}\text { Charac- } \\
\text { teristic }\end{array}$ & Type genus & Catalase/Oxidase & Major cellular fatty acids & Respiratory quinone \\
\hline 1 & Bruguierivorax & \pm & $\mathrm{C}_{16: 0}$, feature $3\left(\mathrm{C}_{16: 1} \omega 7 c\right.$ and/or $\left.\left.\mathrm{C}_{16: 1} \omega 6 c\right)\right)$ & MK-8 \& Q-8 \\
\hline 2 & Pectobacterium [38] & \pm & $\mathrm{C}_{16: 0}$, summed feature $3\left(\mathrm{C}_{16: 1} \omega 7 c\right.$ and/or $\left.\mathrm{C}_{16: 1} \omega 6 c\right)$ & MK-8 \& Q-8 \\
\hline 3 & Erwinia [39] & \pm & $\mathrm{C}_{16: 0}$, summed feature $3\left(\mathrm{C}_{16: 1} \omega 7 c\right.$ and/or $\left.\mathrm{C}_{16: 1} \omega 6 c\right)$ & Q-8 \\
\hline 4 & Escherichia [40-42] & \pm & $\mathrm{C}_{16: 0}$, summed feature $3\left(\mathrm{C}_{16: 1} \omega 7 c\right.$ and/or $\left.\mathrm{C}_{16: 1} \omega 6 c\right), \mathrm{C}_{17: 0}$ cyclo & Q-8 \\
\hline 5 & Yersinia [43-45] & $+/ \mathrm{nd}$ & $\mathrm{C}_{16: 0}, \mathrm{C}_{18: 1} \omega 7 c$, summed feature $3\left(\mathrm{C}_{16: 1} \omega 7 c\right.$ and/or $\left.\mathrm{C}_{16: 1} \omega 6 c\right)$ & MK-8 \& Q-8 \\
\hline 6 & Morganella $[46,47]$ & $\mathrm{nd} /-$ & $\mathrm{C}_{16: 0}$ & nd \\
\hline 7 & Hafnia [48] & \pm & $\mathrm{C}_{16: 0}$ and $\mathrm{C}_{17: 0}$ cyclo & nd \\
\hline 8 & Budvicia [49] & \pm & $\mathrm{C}_{16: 0}$, summed feature $3\left(\mathrm{C}_{16: 1} \omega 7 c\right.$ and/or $\left.\mathrm{C}_{16: 1} \omega 6 c\right)$ & MK-8 \& Q-8 \\
\hline
\end{tabular}

Families: 1, Bruguierivoracaceae; 2, Pectobacteriaceae; 3, Erwiniaceae; 4, Enterobacteriaceae; 5, Yersiniaceae; 6, Morganellaceae; 7, Hafniaceae; 8 , Budviciaceae. + , positive; - , negative, nd, not determined

\section{Phylogenetic Analyses}

The nearly complete $16 \mathrm{~S}$ rRNA gene sequence of strain BGMRC $2031^{\mathrm{T}}$ (1472 nucleotides) has been deposited in National Center for Biotechnology Information (NCBI GenBank) under accession No. MN059649. Alignment based on the 16S rRNA gene sequence in the EzBioCloud database indicated that strain BGMRC $2031^{\mathrm{T}}$ is a member of the order Enterobacterales and showed the highest 16S rRNA gene sequence similarity to $S$. praecaptivus $\mathrm{HS}^{\mathrm{T}}{ }^{\mathrm{T}}(95.6 \%$ sequence similarity), B. tofi DSM $19580^{\mathrm{T}}$ (95.5\%), S. glossinidius DSM $16929^{\mathrm{T}}(95.4 \%)$, Candidatus S. melophagi $\mathrm{CZ}^{\mathrm{T}}$ (95.3\%), Candidatus S. baculum $\mathrm{HBA}^{\mathrm{T}}$ (91.5\%), and Brenneria goodwinii $\mathrm{FRB} 141^{\mathrm{T}}$ (94.9\%), suggesting that it is a novel species. This suggested that strain BGMRC $2031^{\mathrm{T}}$ represented a novel species. Phylogenetic analysis based on the neighbor-joining algorithm revealed that strain BGMRC $2031^{\mathrm{T}}$ and Sodalis lignotolerans 159R (MT536229) cluster together on a single branch. Meanwhile, Strain BGMRC $2031^{\mathrm{T}}$, genera Biostraticola and Sodalis formed a distinct branch in the robust clade (Fig. 1). The maximum-parsimony and maximum-likelihood algorithms showed similar topologies and strains BGMRC $2031^{\mathrm{T}}$, genera Biostraticola and Sodalis forming a separate unified cluster suggesting that BGMRC $2031^{\mathrm{T}}$, Biostraticola, and Sodalis as a single novel family in the order Enterobacterales. (Supplementary Materials Figs. S1 and S2).

The whole-genome-based phylogenetic tree was reconstructed based on the protein sequence using the up-to-date bacterial core gene set (UBCG v.3) according to its manual [36]. The tree showed that strain BGMRC $2031^{\mathrm{T}}$ as well as Biostraticola and Sodalis formed an independent monophyletic clade in parallel with the species in the families Enterobacteriaceae, Erwiniaceae, Pectobacteriaceae, Yersiniaceae, Hafniaceae, Morganellaceae, and Budviciaceae within the order Enterobacterales of the class Gammaproteobacteria and represented a distinct family with the family
Pectobacteriaceae and Erwiniaceae as the closest neighbor (Fig. 2), supporting that strain BGMRC $2031^{\mathrm{T}}$ as well as the genera Biostraticola and Sodalis represented a family-level taxon.

\section{Genomic Characterization}

The draft genome sequences of B. tofi DSM $19580^{\mathrm{T}}, S$. praecaptivus $\mathrm{HS}^{\mathrm{T}}$, and $S$. glossinidius DSM $16929^{\mathrm{T}}$ were obtained from NCBI (Table 3). The genome sequencing depth of strain BGMRC $2031^{\mathrm{T}}$ was $199 \times$, and its N50 and L50 values were 147,949 bp and 12, respectively. Compared with the reference strain, the largest genome size was observed for strain BGMRC $2031^{\mathrm{T}}(5.66 \mathrm{Mb})$. The DNA $\mathrm{G}+\mathrm{C}$ content of strain BGMRC $2031^{\mathrm{T}}$ was determined to be $55.4 \mathrm{~mol} \%$, which was higher than that of $B$. tofi DSM $19580^{\mathrm{T}}(53.9 \%)$ and S. glossinidius DSM $16929^{\mathrm{T}}(54.4 \%)$, but lower than that of S. praecaptivus $\mathrm{HS}^{\mathrm{T}}$ (57.1\%), Candidatus S. baculum HBA, and S. lignotolerans 159R. The ANI values between strain BGMRC $2031^{\mathrm{T}}$ and B. tofi DSM $19580^{\mathrm{T}}$, S. praecaptivus $\mathrm{HS}^{\mathrm{T}}{ }^{\mathrm{T}}$, S. glossinidius DSM $16929^{\mathrm{T}}$, Candidatus S. baculum HBA, and S. lignotolerans 159R were $73.1 \%, 74.7 \%, 74.2 \%, 71.24 \%$, and $77.69 \%$, respectively, which are below the standard ANI criteria for prokaryotic species identity (95-96\%) [37]. The DDH estimated values between strain BGMRC $2031^{\mathrm{T}}$ and $B$. tofi DSM $19580^{\mathrm{T}}$, S. praecaptivus $\mathrm{HS}^{\mathrm{T}}{ }^{\mathrm{T}}$, S. glossinidius DSM $16929^{\mathrm{T}}$, Candidatus S. baculum HBA and S. lignotolerans $159 \mathrm{R}$ were $20.5 \%, 21.1 \%, 21.1 \%, 26.4 \%$, and $26.8 \%$, respectively, which were all much lower than the standard criteria $(\mathrm{DDH}<70 \%)$ [36]. These findings confirmed that strain BGMRC $2031^{\mathrm{T}}$ represents a novel species.

An overview of some characteristics of the respective gene content of the strain BGMRC $2031^{\mathrm{T}}$, B. tofi, S. praecaptivus, $S$. glossinidius, Candidatus $S$. baculum, and $S$. lignotolerans $159 \mathrm{R}$ was given in Table 4 . The genomes of 


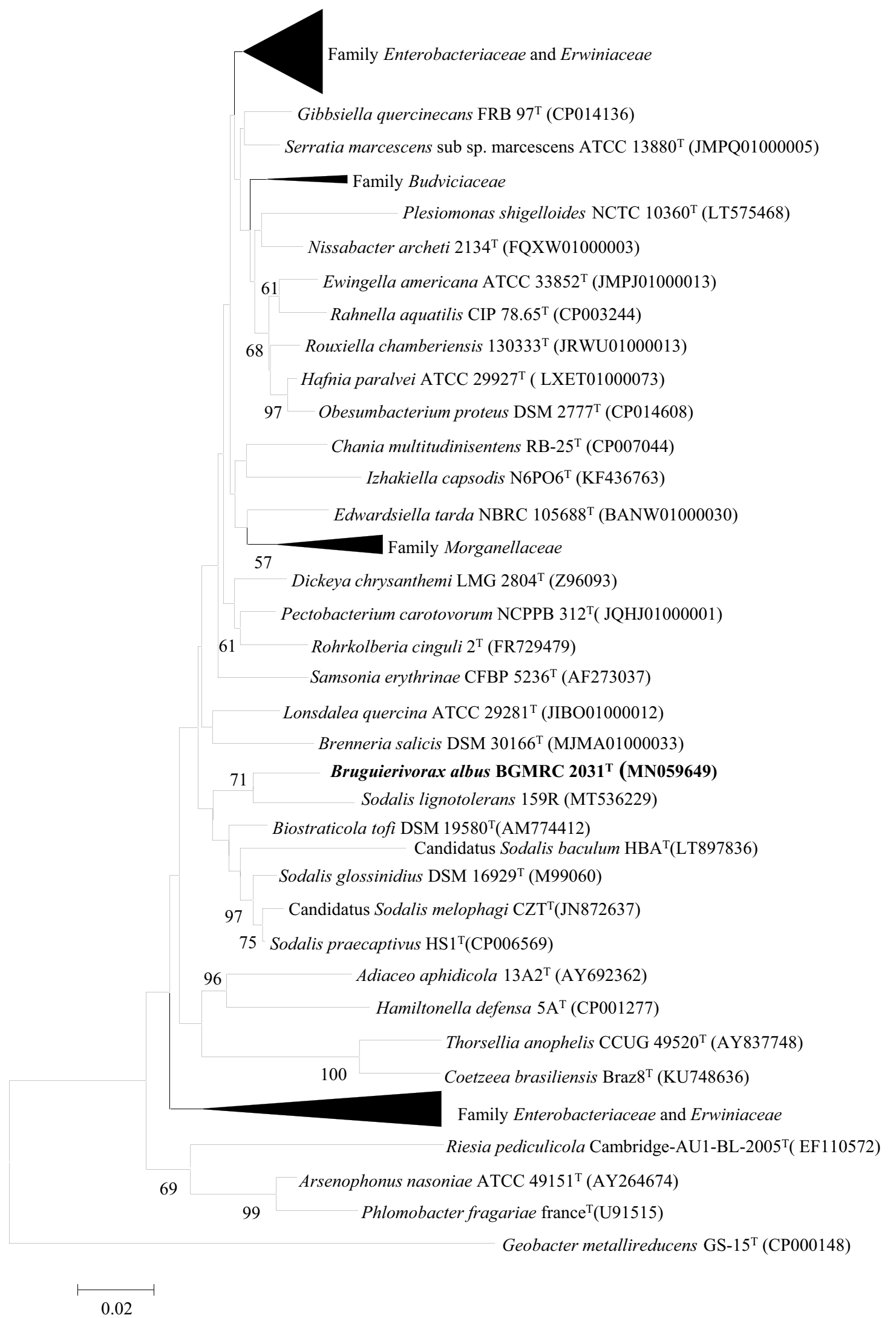


4Fig. 1 Neighbor-joining phylogenetic tree based on 16S rRNA gene sequences, showing the position of the BGMRC $2031^{\mathrm{T}}$ with related taxa. The sequence of Geobacter metallireducens GS- $15^{\mathrm{T}}$ was used as an outgroup. Asterisks indicate that the corresponding branches were also recovered in trees generated with the maximum-likelihood and maximum-parsimony methods. Numbers at nodes indicate the percentage of 1000 bootstrap replicates. Only bootstrap values above $50 \%$ are shown. Bar, 0.02 substitutions per nucleotide position

the strain BGMRC $2031^{\mathrm{T}}$ shared the presence of a riboflavin synthesis gene cluster with the strain $S$. praecaptivus $\mathrm{HS}^{\mathrm{T}}$, S. glossinidius, and Candidatus S. baculum. Furthermore, the new type strains shared the lack of genes encoding soluble cytochrome b562 with those strains. Genes putatively encoded for the aminopeptidases and anaerobic respiratory reductases were only found in the genomes of the new taxon.

\section{Effects on Lifespan of Caenorhabditis elegans}

The mean survival times (\% vs DMSO) of the worms pretreated with strain BGMRC $2031^{\mathrm{T}}$ and blank control are shown in Fig S5. The lifespan of worms treated with BGMRC $2031^{\mathrm{T}}$ extract did not differ significantly from that of the worms treated with the blank control (0.1\% DMSO), which extended the mean lifespan and maximum lifespan by $4.5 \%$ and $12.5 \%$, respectively.

In summary, the unique phenotypic characteristics, principal fatty acid composition $\left(\mathrm{C}_{16: 0}\right.$ and iso- $\mathrm{C}_{16: 1}$ and/or $\mathrm{C}_{14: 0}$ $3-\mathrm{OH})$ and polar lipid composition, as well as the similar respiratory quinone composition and DNA G+C content indicated that strain BGMRC $2031^{\mathrm{T}}$ may represent a novel species in a new genus of a novel family. Low 16S rRNA gene similarities $(\leq 95.6 \%)$, ANI values $(\leq 74.7 \%)$ and DDH values $(\leq 21.1 \%)$ coupled with phenotypic and chemotaxonomic characteristics support that strain BGMRC $2031^{\mathrm{T}}$ represents a novel taxon. Additionally, phylogenetic analyses indicated strain BGMRC $2031^{\mathrm{T}}$ together with the genera Biostraticola and Sodalis represent a novel family within the order Enterobacterales of class Gammaproteobacteria.

\section{Description of Bruguierivoracaceae fam. nov.}

Bruguierivoracaceae (Bru. gui. e. ri. vo. ra. ca. ce'ae. N.L. masc. n. Bruguirerivorax a bacterial genus; -aceae ending to denote family; N.L. fem. pl. n. Bruguierivoracaceae the Bruguierivorax family).

The major fatty acids of family Bruguierivoracaceae are $\mathrm{C}_{16: 0}$ and feature $3\left(\mathrm{C}_{16: 1} \omega 7 \mathrm{c}\right.$ and/or $\left.\mathrm{C}_{16: 1} \omega 6 \mathrm{c}\right)$. Major respiratory quinones are MK-8 and Q-8. The 16S rRNA genebased and phylogenomic analysis showed that the genus Bruguierivorax, Biostraticola and Sodalis forms a separate phylogenetic clade. The family Bruguierivoracaceae contains the type genus Sodalis [3] and the genera Biostraticola [2] and Bruguierivorax. These bacteria are motile rod-shaped, catalase positive, and oxidase negative, and do not produce hydrogen disulfide. Members of this family produce acid from $\mathrm{N}$-acetylglucosamine and are negative for orthinine decarboxylase lysine decarboxylase. The family Bruguierivoracaceae belongs to the order Enterobacterales of the class Gammaproteobacteria.

\section{Description of Bruguierivorax gen. nov.}

Bruguierivorax (Bru.gui.e.ri.vo'rax. N.L. n. Bruguiera a mangrove plant genus; L. masc. adj. vorax devouring, ravenous, voracious; N.L. masc. n. Bruguierivorax, Bruguiera devouring).

Cells are Gram-negative, aerobic, motile, rod-shaped, catalase positive, and oxidase negative. Acid is produced from 2-ketogluconate, dulcitol, D-adonitol and D-mannose. The major respiratory quinones are MK-8 and Q-8. The major polar lipids are phosphatidyl methyl ethanolamine, phosphatidyl glycerol, diphosphatidyl glycerol, phosphatidyl inositol, one unidentified phospholipid and one unknown polar lipid. The type species is Bruguierivorax albus.

\section{Description of Bruguierivorax albus sp. nov.}

Bruguierivorax albus (al'bus. L. masc. adj. albus white, referring to the color of the colonies).

Cells are usually $0.4-0.6 \mu \mathrm{m}$ wide and $1.0-1.6 \mu \mathrm{m}$ long. After 2 days of incubation on ISP2 agar at $28^{\circ} \mathrm{C}$, colonies are circular, smooth, white and round and $0.5-1.5 \mathrm{~mm}$ in diameter. Noval strain grew well on ISP2 agar, LB agar and R2A agar, but no growth occurred on ISP3, ISP4, ISP5, ISP7, nutrient agar or trypticase soy yeast agar plates. Optimum growth occurred at $28^{\circ} \mathrm{C}$, at pH 7.0-8.0 and in the presence of $0-1 \%(\mathrm{w} / \mathrm{v}) \mathrm{NaCl}$. The strain was negative for gelatin hydrolysis, nitrate reduction, hydrolysis of cellulose, starch, and Tween 20, 40, and 80 tests, while it was positive for milk coagulation and peptonisation tests. The strain was positive for O-nitrophenyl- $\beta$ D-galactopyranoside, VP, glucose fermentation, mannitol fermentation, sorbitol fermentation, amygdalin, rhamnose, and $\mathrm{NO}_{2}$. The alkaline phosphatase, leucine arylamidase, valine arylamidase, cystine arylamidase, trypsin, acid phosphatase, naphthol-AS-BI-phosphohydrolase and $\beta$-galactosidase activities were positive of new strain. New strain produced acid from D-arabinitol, L-arabinitol, D-adonitol, 5-ketogluconate, 2-ketogluconate, D-glucose, D-arabinose, L-arabinose, D-mannitol, dulcitol, D-mannose, D-ribose, D-trehalose, L-fucose, D-fructose, D-sorbitol, D-galactose, L-rhamnose, D-mannose, gluconate, D-xylose and $\mathrm{N}$-acetyl-D-glucosamine. The major fatty acids of new strain were $\mathrm{C}_{16: 0}$, summed feature 2 (iso- $\mathrm{C}_{16: 1}$ and/or $\mathrm{C}_{14: 0}$ 3-OH), summed feature $3\left(\mathrm{C}_{16: 1} \omega 7 c\right.$ and/or $\left.\mathrm{C}_{16: 1} \omega 6 c\right)$, $\mathrm{C}_{12: 0}, \mathrm{C}_{17: 0}$ cyclo, and $\mathrm{C}_{14: 0}$. 
Fig. 2 Whole-genome-based phylogenetic tree constructed using UBCGs (concatenated alignment of 92 core genes) showing the phylogenetic relationship of BGMRC $2031^{\mathrm{T}}$ with reference species in the order Enterobacterales of Enterobacterales. Gene support indices (GSIs) are given at branching points. Bar, 0.05 substitution per position
Geobacter metallireducens GS-15 (AGJM00000000)

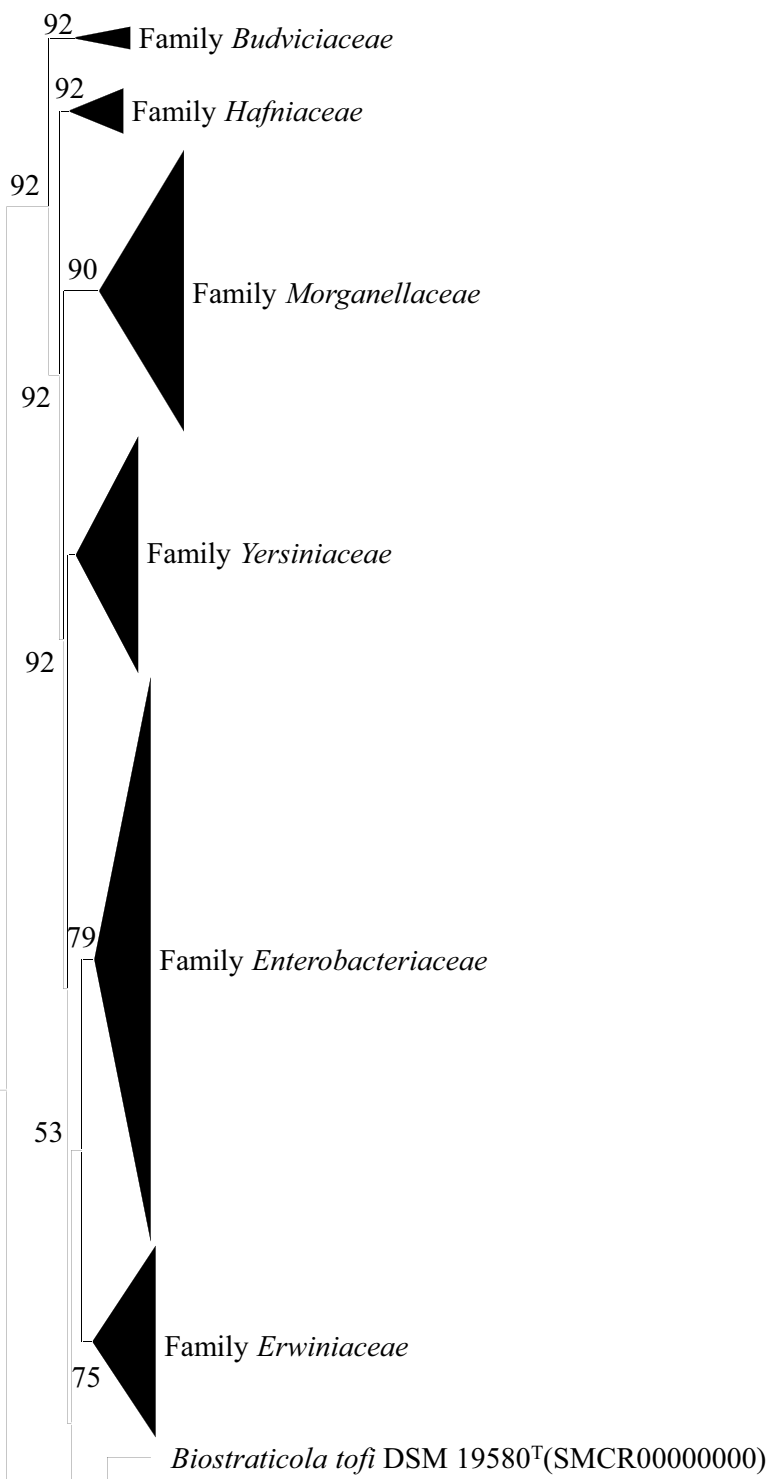

$92100 \quad$ Bruguierivorax albus BGMRC $2031^{\mathrm{T}}$ (SZPQ00000000) Sodalis lignotolerans 159R (NZSJOI01000001)

92 - Sodalis glossinidius morsitans (GCA_900004845.1)

92 Candidatus Sodalis baculum $\mathrm{HBA}^{\mathrm{T}}(\mathrm{LT} 897836)$

64

$92 \leftarrow$ Sodalis praecaptivus $\mathrm{HS}^{\mathrm{T}}(\mathrm{CP} 006569.1)$

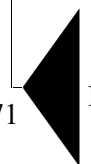

Plesiomonas shigelloides NCTC $10360^{\mathrm{T}}$ (GCA_900087055.1) 
Table 3 Genome characteristics of related strains and BGMRC $2031^{\mathrm{T}}$

\begin{tabular}{|c|c|c|c|c|c|c|}
\hline Characteristic & 1 & 2 & 3 & 4 & 5 & 6 \\
\hline $16 \mathrm{~S}$ similarity $(\%)$ & 100.0 & 95.49 & 95.56 & 95.42 & 91.28 & nd \\
\hline Contigs & 188 & 32 & 2 & 4 & 1 & 1 \\
\hline Total length (bp) & 566,116 & 429,087 & 515,942 & 430,208 & 16,224 & 307,533 \\
\hline ANI $(\%)$ & 100 & 73.16 & 74.71 & 74.18 & 71.24 & 77.69 \\
\hline $\mathrm{DDH}(\%)$ & 100 & 29.9 & 26.5 & 26.2 & 26.4 & 26.8 \\
\hline N50 value (bp) & 147,949 & 391,830 & 4,709 & $4,171,874$ & $1,622,395$ & 11,593 \\
\hline L50 values & 12 & 4 & 1 & 1 & 1 & 80 \\
\hline Genome size (Mbp) & 5.66 & 4.29 & 5.16 & 4.31 & 1.62 & 3.08 \\
\hline $\mathrm{G}+\mathrm{C}$ content $(\mathrm{mol} \%)$ & 55.4 & 53.9 & 57.1 & 54.4 & 36.8 & 56.4 \\
\hline GenBank accession number & SZPQ00000000 & SMCR00000000 & СР006569.1 & GCA_000010085.1 & LT897836 & SJOI00000000 \\
\hline
\end{tabular}

Strains: 1, BGMRC 2031 ${ }^{\mathrm{T}}$; 2, Biostraticola tofi DSM $19580^{\mathrm{T}}$; 3, Sodalis praecaptivus $\mathrm{HS}^{\mathrm{T}}$; 4, Sodalis glossinidius DSM 16929 ${ }^{\mathrm{T}}$; 5, Candidatus Sodalis baculum HBA; 6, Sodalis lignotolerans 159R, nd, not determined

Table 4 Comparison of the presence and absence of selected genes in related strains and BGMRC $2031^{\mathrm{T}}$

\begin{tabular}{|c|c|c|c|c|c|c|}
\hline Genes putatively encoding & 1 & 2 & 3 & 4 & 5 & 6 \\
\hline \multicolumn{7}{|l|}{ Oxidative phosphorylation/energy metabolism } \\
\hline Phosphate metabolism & + & - & + & + & - & + \\
\hline Anaerobic respiratory reductases & + & - & - & - & - & - \\
\hline Aminopeptidases & + & - & - & - & - & + \\
\hline \multicolumn{7}{|l|}{ Motility } \\
\hline Flagellar motility & + & - & - & + & - & + \\
\hline \multicolumn{7}{|l|}{ Electron transport chain } \\
\hline Terminal cytochrome d ubiquinol oxidases & + & + & - & - & + & - \\
\hline Terminal cytochrome oxidases & + & + & - & + & + & - \\
\hline Biogenesis of c-type cytochromes & + & + & - & + & - & + \\
\hline \multicolumn{7}{|l|}{ Other } \\
\hline Trehalose biosynthesis & + & + & + & + & - & + \\
\hline Denitrifying reductase gene clusters & + & - & - & + & - & + \\
\hline Non-mevalonate branch of isoprenoid biosynthesis & + & - & - & - & - & + \\
\hline Ammonia assimilation & + & - & - & - & - & + \\
\hline $\begin{array}{l}\text { Common pathway for synthesis of aromatic Com- } \\
\text { pounds (DAHP synthase to chorismate) }\end{array}$ & + & - & + & + & + & - \\
\hline Lysine biosynthesis DAP pathway & + & - & - & + & + & + \\
\hline Riboflavin synthesis cluster & + & - & + & + & + & + \\
\hline Pyridoxin (Vitamin B6) biosynthesis & + & + & + & + & + & + \\
\hline Flavodoxin & + & - & + & + & + & + \\
\hline Nitrogen fixation & + & - & - & + & - & + \\
\hline Biotin biosynthesis & + & - & + & + & - & + \\
\hline Soluble cytochrome b562 & - & - & - & + & - & - \\
\hline
\end{tabular}

Strains: 1, BGMRC $2031^{\mathrm{T}}$; 2, Biostraticola tofi DSM $19580^{\mathrm{T}} ; 3$, Sodalis praecaptivus $\mathrm{HS}^{\mathrm{T}} ; 4$, Sodalis glossinidius DSM 16929 ${ }^{\mathrm{T}}$; 5, Candidatus Sodalis baculum HBA; 6, Sodalis lignotolerans 159R
This type strain BGMRC $2031^{\mathrm{T}}$ was isolated from the sediment of B. gymnorrhiza root collected from Guangxi Province $\left(=\right.$ NBRC $111907^{\mathrm{T}}=$ KCTC 52119 $)$. The GenBank accession number assigned for the 16S rRNA gene sequence of strain BGMRC $2031^{\mathrm{T}}$ was MN059649. The Whole-Genome Shotgun project of strain BGMRC $2031^{\mathrm{T}}$ has been deposited in DDBJ/ENA/GenBank under accession number SZPQ00000000. 
Funding This funding was supported by Natural Science Foundation of China [Grant Nos. 21662006, 81903533], Natural Science Foundation of Guangxi [Grant No. 2018GXNSFAA281268], Development Program of High-level Talent Team under Qihuang Project of Guangxi University of Chinese Medicine [Grant No. 2018006], The Research Launching Fund Project from Guangxi University of Chinese Medicine Introduced the Doctoral in 2017 [Grant No. 2017BS039], Special Program for scientific research project under Institutes of Marine Drugs of Guangxi University of Chinese Medicine [Grant No. 2018ZD005], the key research and development project from Guangxi Science Technology plan [Grant No. AB16380009], Chinese postdoctoral science foundation [Grant No. 2016M602920XB], The Special Fund for Bagui Scholars of Guangxi, Program for Innovative Research Team of High Education and Outstanding Scholar in Guang Xi [Grant No. 2019-52].

Open Access This article is licensed under a Creative Commons Attribution 4.0 International License, which permits use, sharing, adaptation, distribution and reproduction in any medium or format, as long as you give appropriate credit to the original author(s) and the source, provide a link to the Creative Commons licence, and indicate if changes were made. The images or other third party material in this article are included in the article's Creative Commons licence, unless indicated otherwise in a credit line to the material. If material is not included in the article's Creative Commons licence and your intended use is not permitted by statutory regulation or exceeds the permitted use, you will need to obtain permission directly from the copyright holder. To view a copy of this licence, visit http://creativecommons.org/licenses/by/4.0/.

\section{References}

1. Adeolu M, Alnajar S, Naushad S (2016) Genome-based phylogeny and taxonomy of the, Enterobacteriales, proposal for Enterobacterales ord. nov. divided into the families Enterobacteriaceae, Erwiniaceae fam. nov. Pectobacteriaceae fam. nov. Yersiniaceae fam. nov. Hafniaceae fam. nov. Morganellaceae fam. nov., and Budviciaceae fam. nov. Int J Syst Evol Microbiol 66:55-75. https ://doi.org/10.1099/ijsem.0.001485

2. Verbarg S, Frühling A, Cousin S, Brambilla E, Gronow S, Lünsdorf H, Stackebrandt E (2008) Biostraticola tofi gen. nov. spec. nov. a novel member of the family Enterobacteriaceae. Curr Microbiol 56:603-608. https://doi.org/10.1007/s0028 4-008-9133-9

3. Dale C, Maudlin I (1999) Sodalis gen. nov. and Sodalis glossinidius sp. nov., a microaerophilic secondary endosymbiont of the tsetse fly Glossina morsitans morsitans. Int J Syst Bacteriol 49:267-275. https://doi.org/10.1099/00207713-49-1-267

4. Chari A, Oakeson KF, Enomoto S, Jackson DG, Fisher MA, Dale C (2015) Phenotypic characterization of Sodalis praecaptivus sp. nov., a close non-insect-associated member of the Sodalisallied lineage of insect endosymbionts. Int J Syst Evol Microbiol 65:1400-1405. https://doi.org/10.1099/ijs.0.000091

5. Chrudimský T, Husník F, Nováková E, Hypša V (2012) Candidatus Sodalis melophagi sp. nov.: phylogenetically independent comparative model to the tsetse fly symbiont Sodalis glossinidius. PLoS ONE. https://doi.org/10.1371/journal.pone.0040354

6. Diego SG, Silva FJ, Shai M, Konrad D, Stefan MK (2017) The all-rounder sodalis: a new bacteriome-associated endosymbiont of the lygaeoid bug Henestaris halophilus (Heteroptera: Henestarinae) and a critical examination of its evolution. Genome Biol Evol 9:2893-2910. https://doi.org/10.1093/gbe/evx202

7. Leifson E (1960) Atlas of bacterial flagellation. Q Rev Biol 242:2. https://doi.org/10.1097/00000441-196108000-00035
8. Gerhardt P, Murray RGE, Wood WA, Krieg NR (1994) Methods for general and molecular bacteriology. USA Society for Microbiol, Washington, DC

9. Choi JH, Seok JH, Cha JH, Cha CJ (2014) Lysobacter panacisoli sp. nov., isolated from ginseng soil. Int J Syst Evol Microbiol 64:2193-2197. https://doi.org/10.1099/ijs.0.062034-0

10. Xu P, Li WJ, Tang SK, Zhang YQ, Chen GZ, Chen HH, Xu LH, Jiang CL (2005) Naxibacter alkalitolerans gen. nov., sp. nov., a novel member of the family Oxalobacteraceae isolated from China. Int J Syst Evol Microbiol 55:1149-1153. https:// doi.org/10.1099/ijs.0.63407-0

11. Kelly KL, Judd DB. ISCC-NBS color-name charts illustrated with centroid colors. Washington, DC: US Government Printing Office 1900-1972.

12. Tindall BJ, Sikorski J, Smibert RA, Krieg NR (2007) Phenotypic characterization and the principles of comparative systematics. In: Reddy CA, Beveridge TJ, Breznak JA, Marzluf GA, Schmidt TM et al (eds) Methods for general and molecular microbiology. USA Society for Microbiol, Washington, DC

13. Gonzalez C, Gutierrez C, Ramirez C (1978) Halobacterium vallismortis sp. nov. an amylolytic and carbohydrated-metabolizing, extremely haloppilic bacterium. Can J Microbiol 24:710 715. https://doi.org/10.1139/m78-119

14. Kamekura M (1993) Lipids of extreme halophiles. In: Vreeland RH, Hochstein LI (eds) The biology of halophilic bacteria. CRC Press, Boca Raton, pp 135-161

15. Minnikin DE, O’Donnell AG, Goodfellow M, Alderson G, Athalye M, Schaala A, Parlet JH (1984) An integrated procedure for the extraction of bacterial isoprenoid quinones and polar lipids. Appl Environ Microbiol 2(5):233-241. https://doi. org/10.1016/0167-7012(84)90018-6

16. Komagata K, Suzuki K (1987) Lipid and cell-wall analysis in bacterial systematics. Methods Microbiol 19:161-207. https:// doi.org/10.1016/S0580-9517(08)70410-0

17. Nakagawa Y, Yamasato K (1993) Phylogenetic diversity of the genus cytophaga revealed by $16 \mathrm{~S}$ rRNA sequencing and menaquinone analysis. J Gen Microbiol 139:1155-1161. https ://doi.org/10.1099/00221287-139-6-1155

18. Sasser M (1990) Identification of bacteria by gas chromatography of cellular fatty acids, MIDI Technical Note 101. MIDI Inc, Newark, DE

19. Lane DJ (1991) 16S/23S rRNA sequencing. In: Stackebrandt E, Goodfellow M (eds) Nucleic acid techniques in bacterial systematics. Wiley, Chichester, pp 115-175

20. Li WJ, Xu P, Schumann P, Zhang YQ, Pukall R, Xu LH, Stackebrandt E, Jiang CL (2007) Georgenia ruanii sp. nov., a novel actinobacterium isolated from forest soil in Yunnan (China), and emended description of the genus Georgenia. Int J Syst Evol Microbiol 57:1424-1428. https://doi.org/10.1099/ijs.0.64749-0

21. Niu L, Tang T, Song L, Xiong M, Tian J, Zhang K, Hu X, Zhu D (2015) Pullulanibacillus pueri sp. nov., isolated from Pu'er tea. Int J Syst Evol Microbiol 65(7):2167-2171. https://doi. org/10.1099/ijs.0.000239

22. Thompson JD, Gibson TJ, Plewniak F, Jeanmougin F, Higgins DG (1997) The CLUSTAL_X windows interface: flexible strategies for multiple sequence alignment aided by quality analysis tools. Nucleic Acids Res 25:4876-4882. https://doi. org/10.1093/nar/25.24.4876

23. Saitou N, Nei M (1987) The neighbor-joining method: a new method for reconstructing phylogenetic trees. Mol Biol Evol 4(4):406-425. https://doi.org/10.1093/oxfordjournals.molbe v.a040454

24. Felsenstein J (1981) Evolutionary trees from DNA sequences: a maximum likelihood approach. J Mol Evol 17(6):368-376. https://doi.org/10.1007/BF01734359 
25. Fitch WM (1971) Toward defining the course of evolution: minimum change for a specific tree topology. Syst Zool 20:406-416. https://doi.org/10.2307/2412116

26. Kumar S, Stecher G, Tamura K (2016) MEGA7: molecular evolutionary genetics analysis version 7.0 for bigger datasets. Mol Biol Evol 33(7):1870-1874. https://doi.org/10.1093/molbev/ msw054

27. Kimura M (1983) The neutral theory of molecular evolution. Cambridge University Press, Cambridge

28. Felsenstein J (1985) Confidence limits on phylogenies: anapproach using the bootstrap. Evolution 39(4):783-791. https://doi. org/10.1111/j.1558-5646.1985.tb00420.x

29. Li R, Li Y, Kristiansen K, Wang J (2008) SOAP: short oligonucleotide alignment program. Bioinformatics 24(5):713-714. https ://doi.org/10.1093/bioinformatics/btn025

30. Li D, Liu CM, Luo R, Sadakane K, Lam TW (2015) MEGAHIT: an ultra-fast single-node solution for large and complex metagenomics assembly via succinct de Bruijn graph. Bioinformatics 31(10):1674-1676. https://doi.org/10.1093/bioinformatics/btv033

31. Aziz RK, Bartels D, Best AA, DeJongh M, Disz T, Edwards RA, Formsma K, Gerdes S, Glass EM, Kubal M, Meyer F, Olsen GJ, Olson R, Osterman AL, Overbeek RA, McNeil LK, Paarmann D, Paczian T, Parrello B, Pusch GD, Reich C, Steven R, Vassieva O, Vonstein V, Wilke A, Zagnitko O (2008) The RAST server: rapid annotations using subsystems technology. BMC Genomics 9(1):75. https://doi.org/10.1186/1471-2164-9-75

32. Thompson CC, Chimetto L, Edwards RA, Swings J, Stackebrandt E, Thompson FL (2013) Microbial genomic taxonomy. BMC Genomics 14:913. https://doi.org/10.1186/1471-2164-14-913

33. Meier-Kolthoff JP, Auch AF, Klenk HP, Göker M (2013) Genome sequence-based species delimitation with confidence intervals and improved distance functions. BMC Bioinform 14:60. https://doi. org/10.1186/1471-2105-14-60

34. Wang XM, Zhang ZS, Zhou HC, Sun X, Chen XP, Xua NJ (2019) The anti-aging effects of Gracilaria lemaneiformis polysaccharide in Caenorhabditis elegans. Int J Biol Macromol 140:600-604. https://doi.org/10.1016/j.ijbiomac.2019.08.186

35. Yan DM, Wang W, Li M, Jiang L, Yi XX, Gao CH (2018) Diversity of rhizospheric bacteria and its inhibition activity from Sonneratia apetala in Maowei Sea. J Southern Agric 49:1095-1101. https://doi.org/10.3969/j.issn.2095-1191.2018.06.08

36. Na SI, Kim YO, Yoon SH, Ha SM, Baek I, Chun J (2018) UBCG: up-to-date bacterial core gene set and pipeline for phylogenomic tree reconstruction. J Microbiol 56(4):280-285. https://doi. org/10.1007/s12275-018-8014-6

37. Richter M, Rosselló-Móra R (2009) Shifting the genomic gold standard for the prokaryotic species definition. Proc Nat Acad Sci USA 106(45):19126-19131. https://doi.org/10.1073/pnas.09064 12106

38. Li Y, Fang W, Xue H, Liang WX, Wang LF, Tian GZ, Wang XZ, Lin CL, Li X, Piao CG (2015) Brenneria populi sp. nov., isolated from symptomatic bark of Populus $\times$ euramericana canker.
Int J Syst Evol Microbiol 65:432-437. https://doi.org/10.1099/ ijs.0.066068-0

39. Ramírez-Bahena MH, Salazar S, Cuesta MJ, Tejedor C, Igual JM, Fernández-Pascual M, Peix Á (2016) Erwinia endophytica sp. nov., isolated from potato (L.) stems. Int J Syst Evol Microbiol 66:975-981. https://doi.org/10.1099/ijsem.0.000820

40. Ko KS, Choi JY, Kim J, Park MK (2015) Citrobacter bitternis sp. nov. isolated from bitterns. Curr Microbiol 70:894-897. https:// doi.org/10.1007/s00284-015-0810-1

41. Doijad S, Imirzalioglu C, Yao Y, Pati NB, Falgenhauer L, Hain T, Foesel BU, Abt B, Overmann J, Mirambo MM, Mshana SE, Chakraborty T (2016) Enterobacter bugandensis sp. nov., isolated from neonatal blood. Int J Syst Evol Microbiol 66:968-974. https ://doi.org/10.1099/ijsem.0.000821

42. Khunthongpan S, Bourneow C, Kittikun AH, Tanasupawat S, Benjakul S, Sumpavapol P (2013) Enterobacter siamensis sp. nov., a transglutaminase-producing bacterium isolated from seafood processing wastewater in Thailand. J Gen Appl Microbiol 59:135-140. https://doi.org/10.2323/jgam.59.135

43. Ee R, Madhaiyan M, Ji L, Lim YL, Nor NM, Tee KK, Chen JW, Yin WF (2016) Chania multitudinisentens gen. nov., sp. nov., an $\mathrm{N}$-acyl-homoserine-lactone-producing bacterium in the family Enterobacteriaceae isolated from landfill site soil. Int J Syst Evol Microbiol 66:2297-2304. https://doi.org/10.1099/ijsem.0.001025

44. Kämpfer P, Glaeser SP (2015) Serratia aquatilis sp. nov., isolated from drinking water systems. Int J Syst Evol Microbiol 66:407413. https://doi.org/10.1099/ijsem.0.000731

45. Sprague LD, Scholz HC, Amann S, Busse HJ, Neubauer H (2008) Yersinia similis sp. nov. Int J Syst Evol Microbiol 58:952-968. https://doi.org/10.1099/ijs.0.65417-0

46. Kämpfer P, Tobias NJ, Ke LP, Bode HB, Glaeser SP (2017) Xenorhabdus thuongxuanensis sp. nov. and Xenorhabdus eapokensis sp. nov., isolated from Steinernema species. Int J Syst Evol Microbiol 67:1107-1114. https://doi.org/10.1099/ijsem.0.001770

47. Khunthongpan S, Sumpavapol P, Tanasupawat S, Benjakul S, Kittikun AH (2013) Providencia thailandensis sp. nov., isolated from seafood processing wastewater. J Gen Appl Microbiol 59:185190. https://doi.org/10.2323/jgam.59.185

48. Gu Z, Liu Y, Shen L, Liu X, Xiao N, Jiao N, Liu H, Zhou Y, Zhang S (2015) Hafnia psychrotolerans sp. nov., isolated from the Lake Dajiaco in Tibetan Plateau. Int J Syst Evol Microbiol 65:971-974. https://doi.org/10.1099/ijs.0.000049

49. Lang E, Schumann P, Knapp BA, Kumar R, Spröer C, Insam H (2013) Budvicia diplopodorum sp. nov. and emended description of the genus Budvicia. Int J Syst Evol Microbiol 63:260-267. https ://doi.org/10.1099/ijs.0.036749-0

Publisher's Note Springer Nature remains neutral with regard to jurisdictional claims in published maps and institutional affiliations. 